Article

\title{
The Determinants of the Performance of Precious Metal Mutual Funds
}

\author{
Ioannis E. Tsolas $(\mathbb{D}$ \\ School of Applied Mathematics and Physics, National Technical University of Athens, 15780 Athens, Greece; \\ itsolas@central.ntua.gr
}

Received: 24 October 2020; Accepted: 16 November 2020; Published: 18 November 2020

\begin{abstract}
The aim of this paper is to assess the efficiency of a set of 62 precious metal mutual funds (PMMFs) and to explain performance differences between funds using weighted additive data envelopment analysis (DEA) and Tobit regression, respectively. The contribution of this paper is twofold: to provide for the first-time metrics of the relative performance of PMMFs using a particular weighted additive model, namely the range-adjusted measure (RAM), and to explain the performance of the funds by the use of a Tobit model. Results do not suggest positive linkages between RAM-based and standard fund performance metrics (Sharpe ratio and Jensen's alpha). Moreover, for the sample inefficient funds the mean-variance performance hypothesis does not hold. In addition, fund performance based on RAM can be explained by the persistence of the fund and the beta coefficient.
\end{abstract}

Keywords: precious metal mutual funds; efficiency; data envelopment analysis; tobit regression

\section{Introduction}

In recent years, investment in precious metals has increased with a marked transition of resources from physically observable to financial investments. Precious metals seem to have some advantages for diversification; and moreover, they serve as safe havens. Recent surveys on gold ( $\mathrm{O}^{\prime}$ Connor et al. 2015) and precious white metals (i.e., silver, platinum, and palladium) research (Vigne et al. 2017) favor gold mutual funds and exchange traded funds (ETFs) as diversifiers and support a strong relationship between gold and silver ETFs return. Although there are alternative financial investment vehicles available to precious metal investors (e.g., mutual funds, ETFs, futures, and options), the current paper focuses on the performance appraisal of precious metal mutual funds (PMMFs).

The performance appraisal reflects values attributed to funds and it is used by investors to pick up funds. The financial appraisal of a mutual fund scheme involves data gathering and the application of selected techniques, and because of its academic and practical value, it is a crucial area of research in finance. Consequently, a reliable and rigorous method for evaluating and rating the performance of managed funds is now urgently needed (Chen and Lin 2006). Two main research streams on mutual fund performance appraisal are identified in the literature: the first stream includes methods based on Capital Asset Pricing Model (CAPM) and utility theory, and the second stream involves operation research methods such as data envelopment analysis (DEA) (Bravo et al. 2012).

Risk-return analysis of mutual funds in relation to that of the market is used widely by means of Sharpe (1966) and Treynor (1965) indices and Jensen's $\alpha$ (Jensen 1968). The analysis is based on CAPM and depends on the benchmark portfolio used and the risk (i.e., systematic or total). Conventional indicators such as Treynor and Sharpe indices are used when systematic or total risk is measured, respectively. Moreover, Jensen's $\alpha$ may be used to measure the difference between the actual and the expected return of a fund. An approach based on utility theory using compromise programming has been proposed by Bravo et al. (2012). 
DEA (Charnes et al. 1978) is a nonparametric method that is employed to measure the performance of entities using data on input and output variables. It can be used to derive mutual fund performance metrics using measures of risk and investment costs as inputs and returns and other indicators as outputs. DEA assesses the performance of funds relative to the best-in-class funds. Its advantages compared with other approaches used to measure fund performance are that DEA discriminates between efficient and inefficient funds, reveals the reasons for funds being inefficient, and supports necessary actions that must be taken in order to ensure inefficient funds become efficient (Chen and Lin 2006).

The proposed approach in the current research is the weighted additive model, as proposed by Lovell and Pastor (1995). In the current research, a particular vector of weights is specified for this model that turns it to the range-adjusted measure (RAM) of inefficiency (Cooper et al. 1999). In the fund performance appraisal, the RAM of inefficiency summarizes performance in the form of a single score and defines possible changes where the conversion of inputs, such as risk and expense, to outputs (i.e., returns) is inefficient compared with the best performers. The current paper mainly makes two contributions into the relevant literature. First, the performance of a sample of PMMFs is evaluated using nonparametric DEA, particularly RAM, a specific weighted additive model that has advantages over other conventional radial DEA models (Chen et al. 2019). Second, the drivers (i.e., explanatory variables) of fund underperformance are identified using a Tobit model (i.e., a parametric approach).

In the current research, a number of questions are addressed: (1) What are the contributions of input and output variables to the inefficiency of PMMFs? (2) What are the best-in-class PMMFs? (3) Are RAM-based performance measures and conventional fund performance indicators (Sharpe ratio and Jensen's alpha) correlated? (4) Does the mean-variance efficiency hypothesis hold in respect to underperformer funds? (5) What are the drivers of fund underperformance?

The paper is organized as follows: Section 2 briefly reviews the recent DEA studies on mutual fund performance appraisal. Section 3 presents the weighted additive model and its variants and discusses the properties of the RAM of inefficiency. Section 4 presents the data set and describes the selection of input and output variables. Section 5 deals with the presentation and discussion of the results. The final section concludes.

\section{Literature Review}

There is an increasing body of DEA studies on performance appraisal of mutual funds. The relevant works form two main strands of research. The first strand deals with single DEA studies, which consider mutual fund management as a multiple input-output black box process. A large number of works that followed Murthi et al. (1997) lie in this section. These studies use various DEA models to assess fund performance by putting risk measures and transaction costs in the input side of the DEA and return measures and other performance indices in the output side of the DEA. The analysis is based on CCR (Charnes et al. 1978) or BCC (Banker et al. 1984) models with (McMullen and Strong 1998) or without restrictions on input and output weights (Glawischnig and Sommersguter-Reichmann 2010), RAM of inefficiency (Cooper et al. 1999), and the directional distance function proposed by Chambers et al. (1998). In addition to the above models, other approaches include the minimum convex input requirement set (Chang 2004) and the concepts of order-m frontier (Daraio and Simar 2006) and quantile efficiency (Daouia and Simar 2007). Recent reviews on single DEA mutual fund performance studies are provided by Basso and Funari (2016) and Tsolas $(2014,2020)$. The above type of study does not capture the impact of portfolio diversification and may overestimate fund efficiencies, and as a result, another type of study, namely diversification DEA-based studies, was developed firstly by Morey Matthew R. (1999). Recent contributions to diversification DEA modeling are those by Tarnaud and Leleu (2018) and Lin and Li (2020).

The second strand deals with series two-stage DEA studies in which mutual fund management is considered as a system with two processes. In this kind of analysis, two sub-processes are identified, and their efficiencies are measured (Kao 2014). A number of works that followed Premachandra et al. (2012) 
lie in this research strand. Recent contributions to this type of DEA modeling on fund performance evaluation are the works by Galagedera (2018, 2019), Hsieh et al. (2020), and Tsolas (2020).

In both research strands, researchers may aim to identify the drivers of performance. The explanatory variables, along with the DEA ratings, can be used in single DEA models or modeled by regression models in a follow-up stage of the first stage, where the ratings are measured. The use of a second regression analysis stage characterizes the methodological process, which is referred to as a two-stage DEA (Coelli et al. 2005).

Both single black box and series two-stage DEA have been used for the performance appraisal of PMMFs by Tsolas (2014) and Tsolas (2020), respectively. The weighted additive DEA model has not been used so far to evaluate the performance of PMMFs. The current paper fills this gap by employing a specific weighted additive model, namely the RAM of inefficiency; moreover, regression analysis is used to identify the drivers of the underperformance of PMMFs.

There are some benefits to the RAM of inefficiency compared with conventional DEA models, such as CCR and BCC. The input and output values can change freely in the optimization process of the RAM, whereas conventional models require inputs and outputs to change in proportion according to model orientation. Conventional models are based on radial and oriented DEA, i.e., input or output values shift proportionally in the modeling of input or output orientation to derive efficiency ratings, respectively. The performance is overestimated in the event of inefficiency in the radial and oriented DEA, leading to low discriminatory power of the modeling method (Chen et al. 2019). The current study improves upon Tsolas (2014) by using the RAM of inefficiency. This model is superior to the input-oriented BCC model used by Tsolas (2014) because the input-oriented BCC model provides the potential radial reduction of input values while preserving the output constant.

\section{Methods}

Given a set of $n$ PMMFs to be evaluated, where PMMF $\mathrm{PMses}_{j}=\left(x_{1}, \ldots, x_{m}\right) \in R_{+}^{m}$ amounts of input to produce $Y_{j}=\left(y_{1}, \ldots, y_{k}\right) \in R_{+}^{s}$ amounts of output. The inefficiency of $\mathrm{PMMF}_{0}$ with data $\left(X_{0}\right.$, $Y_{0}$ ) stems from the following weighted additive model (Lovell and Pastor 1995):

$$
W A\left(X_{0}, Y_{0} ; W^{-}, W^{+}\right)=\operatorname{Max} \sum_{i=1}^{m} w_{i}^{-} s_{i 0}^{-}+\sum_{r=1}^{k} w_{r}^{+} s_{r 0}^{+}
$$

subject to

$$
\begin{gathered}
\sum_{j=1}^{n} \lambda_{j} y_{r j}-s_{r 0}^{+}=y_{r j 0} \quad \forall r=1,2, \ldots, k \\
\sum_{j=1}^{n} \lambda_{j} x_{i j}+s_{i 0}^{-}=x_{i j 0} \quad \forall i=1,2, \ldots m \\
\sum_{j=1}^{n} \lambda_{j}=1 \\
\lambda_{j}, s_{r 0^{\prime}}^{+} s_{i 0}^{-} \geq 0 \quad \forall j, i, r
\end{gathered}
$$

where $\lambda_{j}$ represents multipliers that are used to construct the mix of the efficient peer funds, $s_{i}^{-} \geq 0, \forall i=1,2, \ldots m, s_{r}^{+} \geq 0, \forall r=1,2, \ldots, k$ are the slacks of inputs and outputs, respectively, and $w^{-}=\left(w_{1}^{-}, \ldots, w_{m}^{-}\right) \in R_{+}^{m}, w^{+}=\left(w_{1}^{+}, \ldots, w_{k}^{+}\right) \in R_{+}^{s}$ are weights that reflect the importance of the slacks of the inputs and outputs. In order to choose such weights there are two options. The first choice is to pick data-dependent weights, and thus obtain an optimal dimensionless value in the objective function (Lovell and Pastor 1995). The second choice is to set weights reflecting value judgments, which represents the intensity of individuals' (e.g., managers) preferences (Thrall 2000). 
The objective function $W A\left(X_{0}, Y_{0} ; W^{-}, W^{+}\right)=\operatorname{Max} \sum_{i=1}^{m} w_{i}^{-} s_{i 0}^{-*}+\sum_{r=1}^{k} w_{r}^{+} s_{r 0}^{+*}$ where * denotes optimality, reflects the inefficiency of $\mathrm{PMMF}_{0}$. Since $s_{r 0}^{+} \geq 0, \forall r=1,2, \ldots, k$ and $s_{i 0}^{-} \geq 0, \forall i=1,2, \ldots m$, the value of $W A\left(X_{0}, Y_{0} ; W^{-}, W^{+}\right)$is greater or equal to zero. The above presented model maximizes the sum of weighted input slacks and weighted output slacks that is used to measure the distance from $\mathrm{PMMF}_{0}$ to the efficciency frontier. The existence of slacks (i.e., values of the objective function greater than zero) indicates inefficiecy and the inefficient fund should increase outputs and reduce inputs at the same time to become efficient.

Different measures are associated with the model presented above depending on the weights that are set. The most known of these measures are the following (Cooper et al. 2011a):

1. The Measure of Inefficiency Proportions (MIP) (Cooper et al. 1999) setting $\left(W^{-}, W^{+}\right)=$ $\left(1 / X_{0}, 1 / Y_{0}\right)$, where $1 / X_{0}=\left(1 / x_{10}, \ldots, 1 / x_{m 0}\right)$ and $1 / Y_{0}=\left(1 / y_{10}, \ldots, 1 / y_{k 0}\right)$;

2. The RAM of inefficiency (Cooper et al. 1999) setting $\left(W^{-}, W^{+}\right)=\left(1 /(m+k) R^{-}, 1 /(m+\right.$ $\left.k) R^{+}\right)$, where $R_{i}^{-}=\max _{1 \leq j \leq n}\left\{x_{i j}\right\}-\min _{1 \leq j \leq n}\left\{x_{i j}\right\}, i=1,2, \ldots m$ and $R_{r}{ }^{+}=\max _{1 \leq j \leq n}\left\{y_{r j}\right\}-$ $\min _{1 \leq j \leq n}\left\{y_{r j}\right\}, r=1,2, \ldots k$ are the ranges of the observed input and output values, respectively;

3. The Bounded Adjusted Measure (BAM) of inefficiency (Cooper et al. 2011b) setting $\left(W^{-}, W^{+}\right)=$ $\left.\left(1 /\left[(m+k)\left(X_{0}-X\right)\right], 1 /\left[(m+k)\left(\bar{Y}-Y_{0}\right)\right]\right)\right)$, where $X=\left(x_{1}, \ldots, x_{m}\right)$ with $x_{i}=\min _{1 \leq j \leq n}\left\{x_{i j}\right\}, i=$ $1,2, \ldots m, \bar{Y}=\left(\bar{y}_{1}, \ldots, \bar{y}_{m}\right)$ with $\bar{y}_{r}=\max _{1 \leq j \leq n}\left\{y_{r j}\right\}, r=1,2, \ldots k$; and

4. The normalized weighted additive model (Lovell and Pastor 1995) setting $\left(W^{-}, W^{+}\right)=$ $\left(1 / \sigma^{-}, 1 / \sigma^{+}\right)$, where $\sigma^{-}=\left(\sigma_{1}^{-}, \ldots, \sigma_{m}^{-}\right)$is the vector of standard deviations of observed inputs and $\sigma^{+}=\left(\sigma_{1}^{+}, \ldots, \sigma_{k}^{+}\right)$is the vector of standard deviations of observed outputs.

The RAM of inefficiency, a non-oriented slacks-based model that takes into account the weighted slacks of both inputs and output in order to derive the performance metric, is the proposed model in current research. RAM of inefficiency is units-invariant, i.e., the model's objective function is dimensionless since the slacks of inputs and output are divided by the range of their observed values (Chen et al. 2019). RAM-based efficiency is calculated as: $1-W A\left(X_{0}, Y_{0} ; W^{-}, W^{+}\right)$.

\section{Data}

A data set of 62 PMMFs (Tsolas 2014) is used in the current paper. Sample data are as of August 2013. The present study utilizes all available PMMFs at that time. Due to the availability of full information on these funds, 62 funds were evaluated. The sample over a 5 -year observation period is considered as a survivorship bias-free sample.

The data set includes figures on net assets, standard deviation, beta coefficient $(\beta)$, annualized returns, transaction costs, Sharpe ratio and Jensen's alpha On the output side of DEA, the annualized 3-year return is used as a variable that reflects the medium-term performance (Galagedera and Silvapulle 2002; Tsolas 2014, 2020). On the input side of the DEA, four variables are considered: (i) standard deviation of 3-year return as a measure of total risk; (ii) management expense ratio (MER) as percentage of net assets that reflects fund management fee charged; (iii) front load (fee charged when shares are purchased); and (iv) deferred load (fee charged when shares are sold by the investors). The RAM of inefficiency is used to analyze whether fund management has effectively used the above inputs to generate output.

Table 1 provides descriptive statistics of the input and output variables used. The list of the sampled PMMFs is given in Appendix A. 
Table 1. Descriptive statistics of the sample precious metal mutual fund (PMMF) data.

\begin{tabular}{cccccc}
\hline $\begin{array}{c}\text { Descriptive } \\
\text { Statistics }\end{array}$ & $\begin{array}{c}\text { 3 Year-Standard } \\
\text { Deviation (\%) }\end{array}$ & $\begin{array}{c}\text { Management Expense } \\
\text { Ratio (MER) (\%) }\end{array}$ & $\begin{array}{c}\text { Frond } \\
\text { Load (\%) }\end{array}$ & $\begin{array}{c}\text { Deferred } \\
\text { Load (\%) }\end{array}$ & $\begin{array}{c}\text { 3 Year-Returns } \\
\text { (\%) }\end{array}$ \\
\hline Min & 25.7 & 0.3 & 0.0 & 0.0 & -26.1 \\
Max & 36.3 & 3.6 & 5.8 & 5.0 & -12.5 \\
Mean & 30.1 & 1.5 & 1.2 & 0.6 & -17.2 \\
Median & 30.0 & 1.3 & 0.0 & 0.0 & -16.7 \\
$\begin{array}{c}\text { Standard } \\
\text { deviation }\end{array}$ & 1.8 & 0.6 & 2.3 & 1.3 & 2.6 \\
\hline
\end{tabular}

The aim of the current study is also to identify the drivers of fund underperformance with the aid of a Tobit regression model, which regresses the funds' RAM of inefficiency on a set of explanatory variables that reflect the funds' features. The candidate explanatory variables include the logarithm of the fund's net assets that reflects the size of the fund, the persistence of the fund (i.e., annualized one-year return), and a low beta/high beta dummy variable indicating if the fund has a low or high beta depending on the sample fund's median beta coefficient. Beta coefficient for mutual funds is a measure of the fund's volatility compared to the market. Beta is calculated using the simple CAPM: the monthly return of the fund is compared to the performance of the S\&P 500, and the risk-free rate is given as the US Treasury bill rate.

\section{Results}

The current section firstly presents and discusses the results of the first stage RAM-based performance and then provides and discusses the findings of the second stage Tobit regression.

Table 2 depicts the RAM-based efficiency scores of PMMFs resulting from the use of RAM as a basic weighted additive model. The average efficiency of sampled funds is about $76 \%$, whereas the median efficiency is about $75 \%$. Of the 62 funds of the sample, 4 (6\% of the total) are relatively efficient. The average efficiency of inefficient funds is about $75 \%$, whereas the median efficiency is about $74 \%$.

Table 2. Descriptive statistics of RAM-based efficiency (total sampled and inefficient funds). Number and percentage of efficient PMMFs.

\begin{tabular}{cccccc}
\hline RAM-Based Efficiency & $\begin{array}{c}\text { Mean (Standard } \\
\text { Deviation) }\end{array}$ & Median & Min & Max & $\begin{array}{c}\text { Efficient Funds, } \\
\text { Number (\%) }\end{array}$ \\
\hline $\begin{array}{c}\text { Efficient and inefficient } \\
\text { funds }\end{array}$ & $76.3 \%(12.5 \%)$ & $75.1 \%$ & $48.1 \%$ & $100.0 \%$ & $4(6 \%)$ \\
Inefficient funds & $74.6 \%(11.2 \%)$ & $74.0 \%$ & $48.1 \%$ & $93.1 \%$ & \\
\hline
\end{tabular}

Using the results of RAM-based efficiency, the best-in-class funds are: SGGDX, FEGOX, FEGIX, and VGPMX. The results compared to those by Tsolas (2014) provide the same best-in-class funds; the Spearman's and Kendall's rank correlation coefficients are 0.59 and 0.44 , respectively. For the case of robustness, another variant of weighted additive DEA model was used, namely the normalized weighted additive model. The results of this model also provide the same funds as best-in-class funds. Moreover, the RAM of efficiency is produced using the beta coefficient instead of standard deviation as a measure of risk. The best-in-class funds in this situation are the following: ACGGX, AGGNX, FEGIX, and VGPMX. Spearman's and Kendall's rank correlation coefficients are 0.88 and 0.75 , respectively for both cases (i.e., using standard deviation or beta coefficient as a risk measure). In both cases, FEGIX and VGPMX are among the best-in-class funds. Details of the results are available from the author.

Table 3 displays the correlation coefficients of RAM-based efficiency and two indicators that are based on the CAPM, namely the Sharpe ratio and Jensen's alpha RAM-based efficiency is not strongly associated with the above conventional indices because of the different perspectives of the metrics. 
Table 3. Correlation matrix among RAM-based efficiency and Sharpe ratio and Jensen's alpha for the sampled PMMFs.

\begin{tabular}{cc}
\hline Correlation Coefficients & \multicolumn{2}{c}{ RAM-Based Efficiency } \\
\hline \multicolumn{2}{c}{ Panel A: Pearson's } \\
\hline Jensen $a$ & $0.56^{*}$ \\
Sharpe index & $0.39^{*}$ \\
\hline \multicolumn{2}{c}{ Panel B: Kendall's } \\
\hline Jensen $a$ & $0.39^{*}$ \\
Sharpe index & $0.26^{*}$ \\
\hline \multicolumn{2}{c}{ Panel C: Spearman's } \\
\hline Jensen $a$ & $0.53 *$ \\
Sharpe index & $0.38^{*}$ \\
\hline
\end{tabular}

* significance at a level of $1 \%$.

It is possible to identify the causes of inefficiency for the inefficient funds by analyzing the input and output slacks. Table 4 depicts the optimum RAM model input and output slacks, presented as proportions of their respective ranges. The inputs with the greatest contribution to inefficiency of PMMFs are risk, front load, and MER. The mean input inefficiencies (about 21\%) are significantly lower than the output inefficiency (33.5\%). A noteworthy finding is that total risk has slacks for all inefficient funds. This is not consistent with the findings of previous DEA studies that mutual funds are mean-variance efficient (Murthi et al. 1997; Tsolas 2014).

Table 4. RAM-based mean slacks in inputs and output expressed as a proportion of their corresponding ranges.

\begin{tabular}{cccccc}
\hline $\begin{array}{c}\text { Input and Output } \\
\text { Variables }\end{array}$ & $\begin{array}{c}\text { 3y-Standard } \\
\text { Deviation (\%) }\end{array}$ & $\begin{array}{c}\text { Management Expense } \\
\text { Ratio (MER) (\%) }\end{array}$ & $\begin{array}{c}\text { Frond } \\
\text { Load (\%) }\end{array}$ & $\begin{array}{c}\text { Deferred } \\
\text { Load (\%) }\end{array}$ & 3y-Returns (\%) \\
\hline $\begin{array}{c}\text { RAM-based mean } \\
\text { slacks }\end{array}$ & $38.5 \%$ & $15.5 \%$ & $19.5 \%$ & $11.6 \%$ & $33.5 \%$ \\
\hline
\end{tabular}

The inefficiency scores stemming from RAM reflect the performance of mutual funds. The explanation for differences in the inefficiency patterns is necessary because performance may be related not only to ineffective fund management but also to other factors. In order to identify the drivers of performance, the RAM of inefficiency is regressed on a set of candidate explanatory variables specified in Section 4 using the Tobit regression. The current analysis uses the inefficiency scores derived from RAM as dependent variables in the Tobit regression. This is in line with Greene (1993), who proposed the use of censoring at zero in the case of Tobit regression. Table 5 depicts the results of the Tobit regression analysis. The results using the whole set of candidate variables are given in the first panel, whereas the results concern only the use of the fund's persistence and the low-beta/high-beta dummy variable in the second panel.

The impact of 1-year returns that controls for fund's persistence and the low-beta/high-beta dummy variable is statistically significant in explaining fund's inefficiency. The sign of the 1-year return variable is negative, as predicted, and the sign of the low-beta/high-beta dummy variable is positive, suggesting that low-beta funds appear to be more effective relative to their counterparts. 
Table 5. Results of Tobit regression for fund inefficiency.

\begin{tabular}{cccc}
\hline Variable & Coefficient & Standard Error & t-Value \\
\hline \multicolumn{4}{c}{ Panel A } \\
\hline Constant & -0.46 & 0.20 & -2.30 \\
SIZE & -0.01 & 0.01 & -1.30 \\
PERSIST & -2.05 & 0.52 & $-3.93^{*}$ \\
BETADUM & 0.08 & 0.03 & $2.60^{*}$ \\
Sigma & 0.11 & 0.01 & \\
& Log likelihood $=39.16$ \\
\hline \multicolumn{4}{c}{ Panel B } \\
Constant & -0.54 & 0.19 & $-2.78^{*}$ \\
PERSIST & -2.03 & 0.53 & $-3.85^{*}$ \\
BETADUM & 0.09 & 0.03 & $3.06^{*}$ \\
Sigma & 0.12 & 0.01 & \\
& Log likelihood $=38.32$ &
\end{tabular}

Dependent variable: RAM of inefficiency; SIZE: logarithm of the fund's net assets; PERSIST: fund annualized 1-year return; BETADUM: a low-beta/high-beta dummy variable that indicates if the fund is a low-beta or a high-beta fund. * significance at a level of $1 \%$.

\section{Conclusions}

The current paper combines DEA (i.e., a nonparametric, data-driven method) with the parametric Tobit regression to analyze the performance of a sample of PMMFs. In particular, the RAM of inefficiency is used as a specific weighted additive DEA model and the produced inefficiency scores are regressed on a set of explanatory variables. The RAM of inefficiency is provided for each of mutual fund of the sample compared with the best funds, as opposed to conventional methodologies.

The current paper aims to provide answers to a set of research questions raised. The findings, which include answers to questions (1) and (2), suggest the following: (i) There is potential for enhancing performance by simultaneously reducing inputs (i.e., risk and other transaction costs) and increasing output (i.e., return). (ii) The derived RAM of inefficiency can be used to differentiate between funds that have excelled in performance. Different models are used to validate the results. Findings, offering answers to question (3), do not indicate positive links between RAM-based efficiency and two indicators that are based on the CAPM, namely the Sharpe ratio and Jensen's alpha, in terms of Pearson's, Kendall's, and Spearman's rank correlation coefficients. For inefficient sample funds, the mean-variance efficiency hypothesis does not hold (question (4)). Furthermore, the results of the Tobit regression model providing answers to question (5) show that fund RAM of inefficiency can be explained by the fund's persistence and the beta coefficient.

The findings of the current study can be used by professionals and investors. More precisely, financial analysts may use the proposed metrics to track the performance of the industry of PMMFs at a sectoral level. Financial investors could gain information on their portfolios through the RAM of inefficiency and may use it for their investment decisions. Managers may be interested in tracking their fund's achievement together with fund management efficacy. The current research helps professionals and investors to set a benchmark for the success of PMMFs, not only taking into account risk, but also fund costs and fees. An understanding of the sampled funds' inefficiency and the factors influencing it can be highly beneficial to both professionals and investors, and it can provide valuable guides for future studies. As for fund managers, more focus should be placed on returns, risk, MER, and front-end load requirements in order to increase the performance of their management funds.

The current study using DEA has certain limitations. First, the use of the DEA is computationally intensive, since it is necessary to solve a separate linear program for each PMMF in the study. Second, data errors can cause problems. Bootstrapping can be used to address uncertainty in the DEA, but no such computer code is available for slack-based models. Finally, the findings are unique to the study, and thus if the number of observed funds is changed, the results will vary. 
This study can be further expanded by evaluating funds for a longer period. For example, it would be interesting to choose a subsequent or prior time period and investigate whether the results are sensitive to the chosen time period.

Funding: This research received no external funding.

Conflicts of Interest: The author declares no conflict of interest.

\section{Appendix A}

The list of the sampled PMMFs is provided in Table A1.

Table A1. List of the sampled PMMFs.

\begin{tabular}{|c|c|}
\hline Symbol & Name \\
\hline ACGGX:US & American Century Global Gold Fund-A \\
\hline AGYCX:US & American Century Global Gold Fund-C \\
\hline AGGNX:US & American Century Global Gold Fund-Institutional \\
\hline BGEIX:US & American Century Global Gold Fund-Investor \\
\hline AGGWX:US & American Century Global Gold Fund-R \\
\hline BWGIX:US & BlackRock World Gold Fund-Institutional \\
\hline BWGAX:US & BlackRock World Gold Fund-Investor A \\
\hline BWGCX:US & BlackRock World Gold Fund-Investor C \\
\hline SGDAX:US & DWS Gold \& Precious Metals Fund-A \\
\hline SGDBX:US & DWS Gold \& Precious Metals Fund-B \\
\hline SGDCX:US & DWS Gold \& Precious Metals Fund-C \\
\hline SGDIX:US & DWS Gold \& Precious Metals Fund-Institutional \\
\hline SCGDX:US & DWS Gold \& Precious Metals Fund-S \\
\hline DWGOX:US & Dynamic Gold \& Precious Metals Fund-I \\
\hline FGDAX:US & Fidelity Advisor Gold Fund-A \\
\hline FGDBX:US & Fidelity Advisor Gold Fund-B \\
\hline FGDCX:US & Fidelity Advisor Gold Fund-C \\
\hline FGDIX:US & Fidelity Advisor Gold Fund-Institutional \\
\hline FGDTX:US & Fidelity Advisor Gold Fund-T \\
\hline FSAGX:US & Fidelity Select Gold Portfolio \\
\hline SGGDX:US & First Eagle Gold Fund-A \\
\hline FEGOX:US & First Eagle Gold Fund-C \\
\hline FEGIX:US & First Eagle Gold Fund-I \\
\hline FKRCX:US & Franklin Gold and Precious Metals Fund-A \\
\hline FGADX:US & Franklin Gold and Precious Metals Fund-Advisor \\
\hline FRGOX:US & Franklin Gold and Precious Metals Fund-C \\
\hline GLDAX:US & Gabelli Gold Fund Inc-A \\
\hline GOLDX:US & Gabelli Gold Fund Inc-AAA \\
\hline GLDCX:US & Gabelli Gold Fund Inc-C \\
\hline GLDIX:US & Gabelli Gold Fund Inc-I \\
\hline IGDAX:US & Invesco Gold \& Precious Metals Fund-A \\
\hline IGDBX:US & Invesco Gold \& Precious Metals Fund-B \\
\hline IGDCX:US & Invesco Gold \& Precious Metals Fund-C \\
\hline FGLDX:US & Invesco Gold \& Precious Metals Fund-INVESTOR \\
\hline IGDYX:US & Invesco Gold \& Precious Metals Fund-Y \\
\hline MIDSX:US & Midas Fund \\
\hline OCMAX:US & OCM Mutual Fund-OCM Gold Fund-Advisor \\
\hline OCMGX:US & OCM Mutual Fund-OCM Gold Fund-Investor \\
\hline OPGSX:US & Oppenheimer Gold \& Special Minerals Fund-A \\
\hline OGMBX:US & Oppenheimer Gold \& Special Minerals Fund-B \\
\hline OGMCX:US & Oppenheimer Gold \& Special Minerals Fund-C \\
\hline OGMNX:US & Oppenheimer Gold \& Special Minerals Fund-N \\
\hline RYMNX:US & Rydex Series-Precious Metals Fund-A \\
\hline RYMPX:US & Rydex Series-Precious Metals Fund-ADVISOR \\
\hline
\end{tabular}


Table A1. Cont.

\begin{tabular}{cc}
\hline \multicolumn{1}{c}{ Symbol } & Name \\
\hline RYZCX:US & Rydex Series-Precious Metals Fund-C \\
RYPMX:US & Rydex Series-Precious Metals Fund-INVESTOR \\
TGLDX:US & Tocqueville Gold Fund/The \\
USERX:US & US Global Investors Gold and Precious Metals Fund \\
UNWIX:US & US Global Investors World Precious Minerals Fund-Institutional \\
UNWPX:US & US Global Investors World Precious Minerals Fund \\
UIPMX:US & USAA Precious Metals and Minerals Fund-Institutional \\
USAGX:US & USAA Precious Metals and Minerals Fund \\
INIVX:US & Van Eck International Investors Gold Fund-A \\
IIGCX:US & Van Eck International Investors Gold Fund-C \\
INIIX:US & Van Eck International Investors Gold Fund-I \\
INIYX:US & Van Eck International Investors Gold Fund-Y \\
VGPMX:US & Vanguard Precious Metals and Mining Fund-Investor \\
EKWAX:US & Wells Fargo Advantage Precious Metals Fund-A \\
EKWDX:US & Wells Fargo Advantage Precious Metals Fund-Administrator \\
EKWBX:US & Wells Fargo Advantage Precious Metals Fund-B \\
EKWCX:US & Wells Fargo Advantage Precious Metals Fund-C \\
EKWYX:US & Wells Fargo Advantage Precious Metals Fund-I \\
\hline
\end{tabular}

\section{References}

Banker, Rajiv D., Abraham Charnes, and William W. Cooper. 1984. Some models for estimating technical and scale inefficiencies in Data Envelopment Analysis. Management Science 30: 1078-92. [CrossRef]

Basso, Antonella, and Stefania Funari. 2016. DEA performance assessment of mutual funds. In Data Envelopment Analysis: A Handbook of Empirical Studies and Applications. Edited by Joe Zhu. New York: Springer, pp. 229-87.

Bravo, Mila, Enrique Ballestero, and David Pla-Santamaria. 2012. Evaluating fund performance by compromise programming with linear-quadratic composite metric: An actual case on the CaixaBank in Spain. Journal of Multi-Criteria Decision Analysis 19: 247-55. [CrossRef]

Chambers, Robert G., Yangho Chung, and Rolf Färe. 1998. Profit, directional distance functions, and Nerlovian efficiency. Journal of Optimization Theory and Applications 98: 351-64. [CrossRef]

Chang, Kuo-Ping. 2004. Evaluating mutual fund performance: An application of minimum convex input requirement set approach. Computers and Operational Research 31: 929-40. [CrossRef]

Charnes, Abraham, William W. Cooper, and Edwardo Rhodes. 1978. Measuring the efficiency of decision making units. European Journal of Operational Research 2: 429-44. [CrossRef]

Chen, Zhiping, and Ruiyue Lin. 2006. Mutual fund performance evaluation using data envelopment analysis with new risk measures. OR Spectrum 28: 375-98. [CrossRef]

Chen, Xiaodong, Ge Wu, and Ding Li. 2019. Efficiency measure on the truck restriction policy in China: A non-radial data envelopment model. Transportation Research Part A: Policy and Practice 129: 140-54. [CrossRef]

Coelli, Timothy J., Dodla Sai Prasada Rao, Christopher J. O’Donnell, and George Edward Battese. 2005. An Introduction to Efficiency and Productivity Analysis, 2nd ed. New York: Springer.

Cooper, William W., Kyung Sam Park, and Jesus T. Pastor. 1999. RAM: A range adjusted measure of inefficiency for use with additive models, and relations to other models and measures in DEA. Journal of Productivity Analysis 11: 5-42. [CrossRef]

Cooper, William W., Jesus T. Pastor, Juan Aparicio, and Fernando Borras. 2011a. Decomposing profit inefficiency in DEA through the weighted additive model. European Journal of Operational Research 212: 411-16. [CrossRef]

Cooper, William W., Jesús T. Pastor, Fernando Borras, Juan Aparicio, and Diego Pastor. 2011b. BAM: A Bounded Adjusted Measure of Efficiency for Use with Bounded Additive Models. Journal of Productivity Analysis 35: 85-94. [CrossRef]

Daouia, Abdelaati, and Leopold Simar. 2007. Nonparametric efficiency analysis: A multivariate conditional quantile approach. Journal of Econometrics 140: 375-400. [CrossRef] 
Daraio, Cinzia, and Leopold Simar. 2006. A robust nonparametric approach to evaluate and explain the performance of mutual funds. European Journal of Operational Research 175: 516-42. [CrossRef]

Galagedera, Don U. A., and Param Silvapulle. 2002. Australian mutual fund performance appraisal using Data Envelopment Analysis. Managerial Finance 28: 60-73. [CrossRef]

Galagedera, Don U.A. 2018. Modelling superannuation fund management function as a two-stage process for overall and stage-level performance appraisal. Applied Economics 50: 2439-58. [CrossRef]

Galagedera, Don U.A. 2019. Modelling social responsibility in mutual fund performance appraisal: A two-stage data envelopment analysis model with non-discretionary first stage output. European Journal of Operational Research 273: 376-89. [CrossRef]

Glawischnig, Markus, and Margit Sommersguter-Reichmann. 2010. Assessing the performance of alternative investments using non-parametric efficiency measurement approaches: Is it convincing? Journal of Banking and Finance 34: 295-303. [CrossRef]

Greene, William H. 1993. Econometric Analysis, 2nd ed. New York: Macmillan.

Hsieh, H. Pierre, Imen Tebourbi, Wen-Min Lu, and Nai-Yu Liu. 2020. Mutual fund performance: The decision quality and capital magnet efficiencies. Managerial and Decision Economics 41: 861-72. [CrossRef]

Jensen, Michael C. 1968. The performance of mutual funds in the period 1945-1964. Journal of Finance 23: 389-416. [CrossRef]

Kao, Chiang. 2014. Network data envelopment analysis: A review. European Journal of Operational Research 239: 1-16. [CrossRef]

Lin, Ruiyue, and Zongxin Li. 2020. Directional distance based diversification super-efficiency DEA models for mutual funds. OMEGA International Journal of Management Science 97: 102096. [CrossRef]

Lovell, C. A. Knox, and Jesús T. Pastor. 1995. Units invariant and translation invariant DEA models. Operations Research Letters 18: 147-51. [CrossRef]

McMullen, Patrick, and Robert A. Strong. 1998. Selection of mutual funds using Data Envelopment Analysis. Journal of Business and Economic Studies 4: 1-12.

Morey Matthew R., Richard C. Morey. 1999. Mutual fund performance appraisals: A multi-horizon perspective with endogenous benchmarking. Omega 27: 241-58. [CrossRef]

Murthi, B. P. S., Yoon K. Choi, and Preyas Desai. 1997. Efficiency of mutual funds and portfolio performance measurement: A non-parametric approach. European Journal of Operational Research 98: 408-18. [CrossRef]

O'Connor, Fergal A., Brian M. Lucey, Jonathan A. Batten, and Dirk G. Baur. 2015. The financial economics of gold-A survey. International Review of Financial Analysis 41: 186-205. [CrossRef]

Premachandra, Inguruwatt M., Joe Zhu, John Watson, and Don U. A. Galagedera. 2012. Best performing US mutual fund families from 1993 to 2008: Evidence from a novel two-stage DEA model for efficiency decomposition. Journal of Banking Finance 36: 3302-17. [CrossRef]

Sharpe, William F. 1966. Mutual fund performance. Journal of Business 39: 119-38. [CrossRef]

Tarnaud, Albane Christine, and Heleu Leleu. 2018. Portfolio analysis with DEA: Prior to choosing a model. OMEGA, The International Journal of Management Science 75: 57-76. [CrossRef]

Thrall, Robert M. 2000. Measures in DEA with an application to the Malmquist index. Journal of Productivity Analysis 13: 125-37. [CrossRef]

Treynor, Jack L. 1965. How to rate management of investment funds. Harvard Business Review 44: 131-36.

Tsolas, Ioannis E. 2014. Precious metal mutual fund performance appraisal using DEA modeling. Resources Policy 39: 54-60. [CrossRef]

Tsolas, Ioannis E. 2020. Precious metal mutual fund performance evaluation: A series two-stage DEA modeling approach. Journal of Risk and Financial Management 13: 87. [CrossRef]

Vigne, Samuel A., Brian M. Lucey, Fergal A. O'Connor, and Larisa Yarovaya. 2017. The financial economics of white precious metals-A survey. International Review of Financial Analysis 52: 292-308. [CrossRef]

Publisher's Note: MDPI stays neutral with regard to jurisdictional claims in published maps and institutional affiliations. 